FIRST PART

\title{
Megaseisms and megatsunamis
}



THE MEGASEISMS AND MEGATSUNAMIS WORKING PARTY, CHAIR AND MEMBERS

Jacques FRIEDEL

Pierre-Yves BARD

Pascal BERNARD

Michel CARA

Vincent COURTILLOT

Jean DERCOURT

Claude JAUPART

Xavier LE PICHON

Raùl MADARIAGA

Jean-Paul MONTAGNER

Alain PECKER

Jean-Paul POIRIER

Jean SALENÇON

François SCHINDELÉ

Paul TAPPONNIER
Président, ancien Président de l'Académie des sciences

Observatoire des sciences de l'Univers de I'université de Grenoble

Institut de physique du globe de Paris

École et Observatoire des sciences de la Terre de l'université de Strasbourg

Académie des sciences

Secrétaire perpétuel honoraire de l'Académie des sciences

Académie des sciences

Académie des sciences

École normale supérieure

Institut de physique du globe de Paris

Académie des technologies

Académie des sciences

Ancien Président de l'Académie des sciences

Commissariat à l'énergie atomique et aux énergies alternatives (CEA)

Académie des sciences 
Personalities invited for a hearing by the Working Party

Rolando ARMIJO Institut de physique du globe de Paris

Robert DAUTRAY Académie des sciences

John DOUGLAS BRGM

Nikolaï SHAPIRO Institut de physique du globe de Paris

Steve TAIT Institut de physique du globe de Paris

\section{Critical review assured by}

$\begin{array}{ll}\text { Alain CARPENTIER } & \text { Président de l'Académie } \\ \text { Philippe TAQUET } & \text { Vice-président de l'Académie } \\ \begin{array}{l}\text { René BLANCHET } \\ \text { et Jean-Louis LE MOUËL }\end{array} & \text { Membres de l'Académie }\end{array}$




\section{Scientific data}

Planet Earth has always been a theatre of internal movements that take place because of the significant differences in temperature and density existing between the Earth's surface and centre. This specific activity takes place between the Earth's crust and the metallic core that extends down more than $3000 \mathrm{~km}$ to the limit of the metallic core. At this extreme depth, the Earth's mantle has a very high temperature and is continuously deformed by warping and creeping phenomena. On the contrary, at the higher levels, the temperatures are low and display an elastic, brittle behaviour, responding to mechanical stresses by sudden jolts, i.e., as occurs in earthquakes.

\subsection{Earthquakes in subduction zones}

In a subduction zone, we can observe how an oceanic plate, denser and colder than the neighbouring mantle, drives itself, because of its weight, under another plate (which may be continental or oceanic, depending on the region) cf. Figure 1.1. This downward progression produces very significant deformation phenomena that release their energy in the form of earthquakes and non-seismic landslides. The largest earthquakes, known also as "megaseisms", have their origins at the frontier between the two plates at depths generally less than $50 \mathrm{~km}$ deep. A simple model that can be used to explain such earthquakes: that of the elastic rebound, initially proposed for the San Andreas Fault after the 1906 earthquake that struck the San Francisco area in 1906 and which was later been adapted to similar occurrences in subduction zones. In what is termed as the inter-seismic phase, between two earthquakes, the deep section of the subduction is sliding forward continuously, slowly but surely building up an accumulation of shear stresses in the upper section, in the so-called "seismogenic zone". This zone is normally blocked by the opposing friction forces that exist between the two plates. Occasionally, the accumulated stress is such that it exceeds the friction threshold value and leads to a brutal shift of the plates: viz., an earthquake takes place. This model explains the jerking movement in a subduction zone, but it does not allow us to calculate the magnitude (or seismic momentum) to be assigned to any given earthquake. Earthquake magnitudes - a logarithmic energy function - depend not only on the distribution pattern of the cumulated stresses generated by movements of the deeper section of the advancing plate, but also on the history of previous earthquakes in the area.

Subduction zone earthquakes take place both inside the plates as well as at the frontier between plates. In Japan (and similarly in the French West Indies), the activity of the upper plate, with the emerged surface islands, is particularly 
Megathrust Earthquake of ||$/ 03 / 20||$

Mw 9.0
Total Rupture

of subduction interface

J A P A N

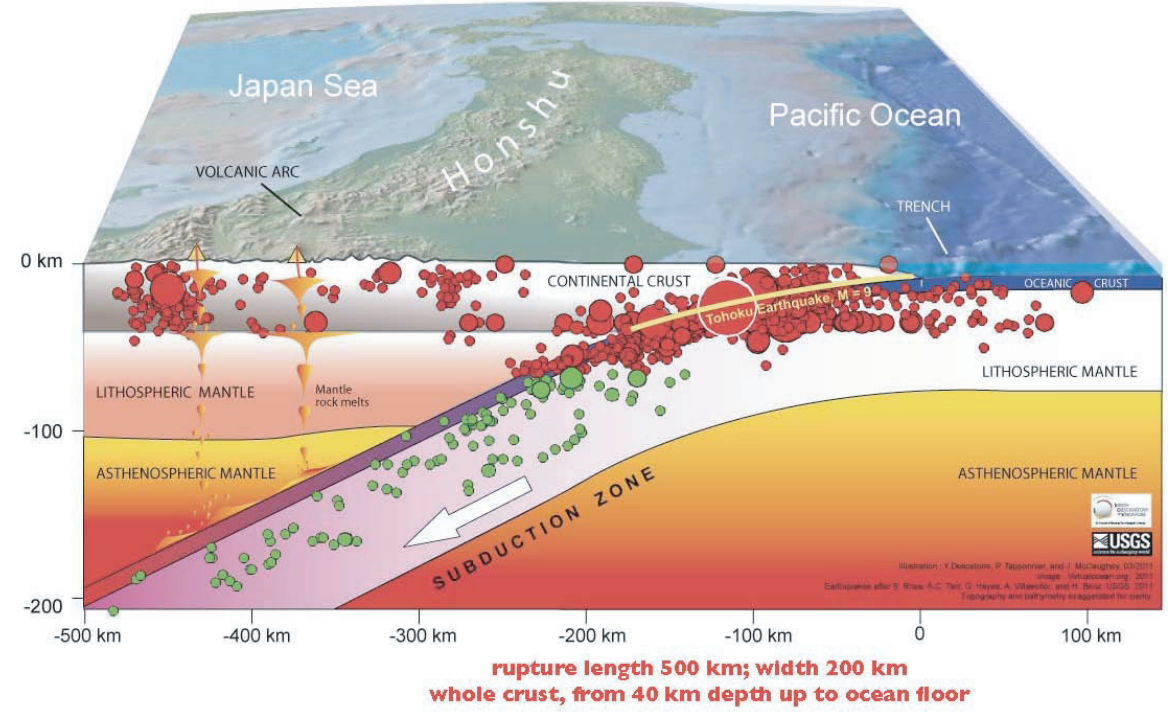

Figure 1.1

Rupture of the subduction zone, March 112011.

significant and leads to highly destructive earthquakes with a magnitude in excess of 8.0. These earthquakes become catastrophic when they occur in or close to inhabited areas. One such earthquake occurred in the "prefecture" of Iwate, North of the city of Sendai in Japan. Important earthquakes also take place inside the oceanic plate and can reach the magnitude of 8.0. Such earthquakes are common in South America and in the West Indies and Caribbean area. Beyond any doubt, the most dangerous earthquakes take place along the frontier between plates and can occasionally exceed the value 8.5; we then are faced with events in the category of megaseisms.

The seismicity of subduction zones complies with several empirical laws, the most important of which is Gutenberg-Richter's law which states that the number of earthquakes of a magnitude higher than a given value will decrease by a factor 10 when the magnitude is increased by one unit. Consequently, the seismicity of a given area depends on the value for the biggest earthquake possible in that subduction zone. In geophysics, this extreme event is called the reference earthquake for that region. However, in most subduction zones, we do not know the scale of the reference earthquake, given that the archives are too recent or are incomplete. This indeed is the case for North-East Japan (Tohoku) where the history of seismic events only goes back 500 years from the 
time Japan began building its nuclear power stations in the mid-seventies. In many subduction zones, the historic catalogues of events can be completed by paloeoseismic data: traces of old tsunamis in the estuaries, or marine ledges or shelves, etc., allow us to reconstitute old earthquakes.

In regard to the Tohoku region, one major paleoseismic event was identified some ten years ago and dated to year 869 AD. When the seismic history is well documented, as is the case in Chile, where megaseisms are more frequent than in Tohoku, we can identify zones where there is a high deficit of seismic slipping, called seismic gaps. These so-called gaps are areas where the shortterm seismic risk is high. This particular analysis allowed us to identify the Maule Fault Gap in Chile where an earthquake of magnitude 8.8 took place on February 27, 2010. More recently - since 1990 approx. - our range of measurements and terrain observations has been augmented by data from space geodesics (using GPS satellites and radar interferometry) and this allows us to estimate the ratio of non-seismic slippage and the rate of accumulation of elastic deformations. Interpreting these data is not easy because the time allotted to a space-borne observation is short compared with the duration of a seismic cycle. Space data has shown that there are non-seismic episodes in the lower sections of a seismogenic zone. It is thought that these slow movements retard the occurrence of megaseisms.

\subsection{Tsunamis}

A tsunami originates in rapid movements of an ocean bed and the amplitude reached by the tsunami wave will be a function of the surface area set in motion, of the amplitude and the direction taken by the wave. It is the vertical movements that are the most dangerous. A tsunami originating in an oceanic basin will progress at a speed that is a simple function relating to the height of the water displaced. Approaching the coast and given the water gets shallower below the tsunami, its speed decreases rapidly and simultaneously the wave gets higher. Also, near the coast - where there is a complex configuration of sea-bed and coastline, with horizontal variations stretching over distances comparable with the depth of water - we observe other wave amplification phenomena that are not yet fully understood today, partly because our data on floor-bed shapes are not totally accurate.

Our knowledge therefore of the probability of a tsunami occurring still remains to be improved. For example, the previous cases December 26, 2004 on Sumatra and March 11,2011 in NE Japan were well in excess of the amplitudes that most seismic specialists had expected given the magnitude of the earthquakes that are expected and fault slips that are largely underestimated; it is above all, it is our knowledge of seismic sources that we need 
to improve with the perspective of such mega-events. The return cycle for events of this magnitude is certainly of the order of a thousand years. In numerous continents, however, the historically recorded period, either oral or in writing, only goes back some centuries, and often, in most cases, less. The available data are therefore very inadequate to correctly assess the definitive probability, all the lower so that the effects of a major tsunami impacts on most of the shorelines of the basin where it occurs and this can be felt up to $20000 \mathrm{~km}$ from the origin. We must often look for the residual effects of a tsunami at a very great distance from its starting point on the globe.

In the case of an earthquake, the characteristic features of a tsunami allow us to work backwards to the initial break-zone and the displacement that takes place along the break. We can also calculate the tsunami characteristics from the estimations of the submarine earthquake. Combining these two approaches, scientists have been able to make significant progress in understanding these events.

\subsection{The Tohoku earthquake, March 1 1, 2011}

The Tohoku earthquake, among those measured by appropriate instruments over the past century, more or less, with its magnitude of 9.0-9.1 is ranked fourth in decreasing order, after Sumatra (2004, 9.1-9.2), Alaska (1964, 9.2) and the biggest earthquake recorded, in Chile $(1960,9.5)$. The break zone for Tohoku measured $600 \mathrm{~km}$ by $250 \mathrm{~km}$, but the area with highest displacement (> $30 \mathrm{~m}$ and locally up to the enormous value of $60 \mathrm{~m}$, was only $100 \mathrm{~km}$ by $50 \mathrm{~km}$ ). Given that the plate convergence rate is estimated at $90-95 \mathrm{~mm} / \mathrm{yr}$ in this region, the deformation that was relieved during this earthquake must have accumulated over at least the past seven centuries. One rather astonishing feature of this earthquake is that two thirds of the break occurred in the area close to the deep ocean trench, where the break plane is a less than $20 \mathrm{~km}$ below the bed. This extremely high break zone was the main source of the gigantic tsunami that built up after the quake. The 1896 earthquake that occurred in the Nord certainly had similar characteristics, the evidence being in the major tsunami that hit the coastline.

The "megaseism" and the "megatsunami", March 11,2011 hit the country that has the most dense network of geophysical observations in the world, with a rapid and highly sophisticate early warning system and the highest antitsunami barriers, a country where the population has the best earthquake training with a long history of acquired experience in these matters, where there is one of the highest levels of scientific achievement and where national disaster management policy based on knowledge acquired from previous events is a major source of concern. The tragic and unexpected consequences 
of this catastrophe were dramatic land would have undoubtedly been much worse if the warning systems had not functioned properly, if the paraseismic quality of the buildings and the training of the populations had not been as good as they were).

The Japanese seismologists responsible for making predictions were convinced that the probability of an earthquake occurring could be calculated in a rational manner, using the definition of reference earthquakes for each region. The forecast map, therefore, had not made any provision for an earthquake of magnitude higher than 7.5 in the area closest to the Asian continent and 8.2 closer to the deep ocean trench. The Tohoku earthquake had a magnitude of 9.0-9.1. On the bases of these forecasts, the tsunamis accompanying the earthquakes were not predicted to exceed 4 to 5 metres on reaching the coast. The Tohoku triggered tsunami measured between 15 to 20 metres. The Fukushima nuclear power station site had been built to protect the infrastructures from tsunamis less than $5.7 \mathrm{~m}$ in height upon reaching the coastline, whereas this tsunami just off the reactor sites measured $14 \mathrm{~m}$ with respect to the sea's normal level.

The main error made by the Japanese specialists was to consider that the past century of seismic events was representative of the continuous, ongoing subduction process. It is, however, known that subduction zones can produce earthquakes equal to or higher than magnitude 9, with lateral movements in excess of 20 to 30 metres, due to stress accumulated over several centuries, i.e., a much longer period than the Japanese specialists had used for their forecasts. The fact that major earthquakes, magnitude 7.5 to 8 had relieved part of the elastic deformation did not preclude that a megaseisms could follow, and indeed this was the case on March 11, 2011. The seismic energy dissipated over the past century only represents $20 \%$ of the energy represented by the progressive dip of the Pacific plate sliding under the Japanese archipelago. In other words, seismicity over a span of one century only accounts for some $20 \mathrm{~mm} / \mathrm{yr}$ progression, i.e., approximately one fifth of the total displacement expected. The hypothesis that there was a permanent regime therefore implied that $80 \%$ of the energy in the plate slipping process was evacuated via microseisms or via plastic slippage.

The geological and historic records show that very big tsunamis had hit the Tohoku coastline in years 1611 and 869, and the residual traces are much greater than those left by the earthquakes over the past century (although the lesser magnitude earthquake that occurred in 1896 did produce some really impressive damage). The cycle for major tsunamis occurring lies between 500 and 1000 years.

The building of a dense GPS network (30 km between the stations) following the Kobe earthquake in 195 allows scientists to demonstrate that the elastic 
deformation observed in Japan as a result of the progressing Pacific Plate corresponded to a slip rate close to $80 \mathrm{~mm} / \mathrm{yr}$, i.e., almost $100 \%$ of the subduction rate and not $20 \%$ as had been conjectured. Japan therefore acts as an efficient blocking system preventing, in essence, the continuous slippage of the Japanese Plate over the subducting Pacific Plate. This "blockage" along the coastline develops a steadily increasing elastic energy in Japan's crust layers, the accumulated energy of which will only be relieved and released when the energy built up exceeds the threshold value for friction between the two plates; Local relaxation may occur, in areas where there is a lower friction value, this explaining the medium magnitude earthquakes that have been observed over the past century. But a total relaxation along the complete subduction trench will occur if the accumulated stress is high enough. The order of magnitude of slippage we are referring to here is compatible with a large slippage of $60 \mathrm{~m}$, as mentioned earlier, that accumulates every seven centuries at least, and this explains the amplitude and the rarity of megaseisms and the associate megatsunamis.

The Tohoku earthquake serves to show that any forecast based on recent data proves inadequate. We must therefore take both historic and geological data into account if we wish to characterise seismicity over a span of at least several centuries, better still over several millenaries. The Tohoku earthquake reinforces a recently proposed idea, that the maximum magnitude that can be attained by a subduction triggered earthquake is $9+$, independently of the subduction progression rate (maximum accumulation of elastic displacement $30 \mathrm{~m}$ approx.). Such a conjecture, as we shall see below, has considerable importance when it comes to assessing the risk factor for seismic activities in the French West Indies.

\section{2 | France}

\subsection{French West Indies (Antilles islands)}

The recent examples provided by earthquakes in Sumatra and Japan have led us in France to reconsider the levels of risk of seeing megaseisms or tsunamis in France. To be precise here, the only area where this might occur is around the French West Indies, with the advancing North American Plate diving below the Caribbean archipelago at a speed of 2 metres per century. The island of Guadeloupe in 2004 experienced a surface earthquake, with magnitude 6.3, leading to a certain amount of destruction in the nearby Saintes archipelago and one death. The island of Martinique in 2007 felt the effects of a deep-lying earthquake, magnitude 7.3; there was no damage or deaths. 
Had that particular earthquake occurred at another location, the effects could have potentially been very serious indeed. We can note, for the record, that these two earthquakes in the French West Indies are considered the two most violent earthquakes on French territory for the past century.

In year 1843, but this was before appropriate instruments existed, a major earthquake, no doubt of a magnitude close to 8 destroyed the town of Pointeà-Pitre on the island of Guadeloupe, but there was no accompanying tsunami. The return cycle for such an event is of the order of several centuries. The recent Japanese (Tohoku) earthquake shows that the Caribbean zone could also be the site of a future megaseism with an extremely long cycle, no doubt exceeding a millenary. In the French West Indies the most ancient chronicles only date from 1492 (Christopher Columbus). It is therefore important to pursue investigations, both on land and at sea in terms of full geological and geophysical analyses (with cooperation throughout the Caribbean Arc) and draw benefit from high resolution space measurements to reconstitute the history of earthquakes and possible tsunamis that may have occurred in this region over several thousand years. Numerous buildings, even those that house public administrations, on both Guadeloupe and Martinique islands do not comply with paraseismic standards that would allow them to resist an earthquake of magnitude 8, even less so one of magnitude 9. Finally let us bear in mind that, on top of seismic risks, there are also risks of strong volcanic activities

\subsection{Mainland ("metropolitan") France}

Mainland or "metropolitan" France has a very different seismic profile than the French (and other) islands in the Caribbean area. The general context is that of the two European and African tectonic plates moving towards each other at an approx. speed of $70 \mathrm{~cm} / \mathrm{yr}$, with a deformation largely absorbed north of the Maghreb countries. It is therefore plausible that an earthquake of magnitude 7.5 in the Maghreb region could lead to a 1-3 m tsunami reaching the Riviera coastline. Correlatively, large scale earthquakes are few and far-between in metropolitan France. History however tells us that earthquakes of a magnitude between 6 and 7 are possible. Their cause would lie mainly in interplay of old, existing faults-lines and a largely unknown deformation field surrounding them. In France, the tectonic context and the influence of significant ground profile variations and their associate stresses are not accurately known as yet. The areas that are seismically most active are the Pyrenean mountain range and the Alps and also France's North-East border region. The Ligurian rim, off the coastline at Nice on the French Riviera is a special case where compression earthquakes can take place below the sea-bed. This indeed is probably what 
happened when certain towns on the coastline East of Nice were shaken in 1887 and when a $2 \mathrm{~m}$ tsunami hit the Mediterranean coast at Cannes and Antibes. Moreover, a vast and somewhat diffuse seismic zone extends from the Massif Central up to the Brittany area known as the Massif Armoricain. The strongest historically recorded earthquakes in France probably never exceeded the magnitude of 7 , but the example just seen in Japan, where the megaseism was bigger than any historically known event in that area, should invite us to reflect on this with caution. We have never recorded any major tsunamis on any of France's coastlines.

Some further geological analyses and accurate dating of seismic markers in the recent quaternary era are definitely needed. On the scale of the millenary, we know that about 10 earthquakes of magnitude 6 or more struck France. There is a famous, historically recorded example, in the city of Basel, where an earthquake in 1356 had a magnitude retrospectively estimated as being between 6 and 7. This sort and scale of earthquake can be highly destructive in a country with a high population density as is the case in France. We need only recall the example of the Lambesc earthquake (not far from Aix-en-Provence, in South France near the Mediterranean), where an earthquake estimated of magnitude 6.2 occurred on June 6, 1909 and killed 46 people in a low-density (at that time) area. Today that earthquake would lead to several hundred dead.

Either through damage to major industrial sites or collapse of older buildings in certain city areas, an earthquake of magnitude 6 can produce many victims and have very serious economic consequences, all then more so if the earthquake's epicentre is close to the surface and to an urban, hence heavily populated, area.

\subsection{Ground response factors}

We now know (and indeed have known for a long time) that local geographic features (nature of the surface layers and of those at lower levels) can modify to a large extent the characteristics of seismic movements and their potential to damage or destroy artefacts. A striking example is provided by the Kashiwasaki-Kariwa nuclear power station site in Japan, where highly heterogeneous three-D effects, moreover variable is strength, depending on the compass direction of the quake, have been duly noted.

The local ground response to seismic quakes are still undergoing lots of research, combining investigations and in situ measurements, with theoretical progress and "heavy" digital simulations. The progress, in fact, has been quite significant, but still remains insufficient since we lack accurate knowledge as to the nature of the lower ground levels beneath most of our major urban cities 
and our industrial sites. These stumbling blocks will only be removed if we resolutely engage in situ instrumentation and underground reconnaissance.

The most recent progress - taken into account at face-value - in paraseismic regulations for "normal risk levels" has been recorded thanks to the enormous efforts in terms of instrumentation and research commitments taken by the Japanese scientists after the Kobe earthquake (Jan. 17, 1995). All the earth movement recording positions have been systematically described thanks to geological and geophysical reconnaissance (drillings, measurement of seismic wave propagation speeds). The seismic community agrees that this is indeed a good example to be followed elsewhere round the world, but regrettably we also note that the funding is missing, notably in Europe. This heavy trend towards total disinterest in soil and terrain recognition has often led to some disagreeable surprises and to significant building over-costing.

\section{3 | Socio-economic considerations}

\subsection{Governance}

Establishing an operational observation system requires a lasting commitment. In most developed countries, it is in the remit of the Home Office to finance surveillance systems. In France, this undertaken lies solely with the Ministry for Higher Education and Research. Most probably, we should be looking for a compromise between the two sorts of organization. If there is no connexion with the research services, the surveillance services can be degraded and ignore the often rapid scientific progress in the area of natural risks. Without funding from the national Home Office, the responsibility carried by the Research ministry is too heavy, and this indeed is the case in France. The State authorities should acquire a systemic organization that would enable them to coordinate various actions taken in respect to major telluric risks (earthquakes, tsunamis, volcanic eruptions, land-slides). After the Soufrière volcano erupted on the island of Guadeloupe in 1976 a High Council for Assessment of Volcanic Risks [CSERV] was appointed (however the CSERV was recently disbanded) and the experience gained served to demonstrate that this body was not functioning properly. There were questions about the competency of the ministry to which the CSERV reported, and indeed of certain public servants who were monitoring the work done. Following the earthquake in 2004 on Sumatra, a "delegate for tsunami alerts" was appointed in the prime minister's office. Unfortunately, Government did not follow through in supporting this position. After an initial investment phase the running costs were cut off and the delegate in essence ceased to exist. It would appear necessary to this Working Party that a body should be re-appointed, reporting to the Prime Minister, with an organisation that would assure co-ordination of 
Government actions should a major telluric event occur, with participation of those ministerial departments in charge of civilian security matters (Home Office), of Higher Education and Research and of the Environment.

We can, however salute the initiative of the French Government to have the CENALT (Alert Centre for Tsunamis) funded by both the French Home Office and the Ministry for Ecology.

The actions to be undertaken without delay in the French West Indies (the Caribbean plate and its Northern and Southern limits), the Lesser Antilles Arc, subduction zone) in respect to mega seisms and the degree of mechanical coupling, should associate high level research and routine observation and surveillance, combining historic, geological, seismological, volcano data, GPS, both inland and at sea. These recommendations are addressed to the ministry in charge of Higher Education and Research, plus the universities and major research establishments, the CNRS notably its Institut national des sciences de l'Univers whose responsibility it is to overview work engaged by the OSU (observatories for studies of the Universe, and certain University research units). INSU is an agency that allocates funding means to the scientists, is in charge of studies of natural milieus (in liaison with the other CNRS Institutes). INSU also provides for supervision and support to the Institut de physique du globe de Paris, and the OSU. Several establishments carry out research in the Caribbean: IPGP notably ensures surveillance of natural phenomena in Guadeloupe and Martinique. The scientific and operation functions of the volcanological and seismological observations in the French West Indies should be underscored.

The funding as needed should be planned and scheduled. Responsibility and budgetary allocations should be clarified (between the ministry for Higher Education and research the CNTRS-INSU, but also the French Home Office where civilian safety is concerned. It was the Institut national des sciences de I'Univers (under a previous statute) that directed the observatories, allocating their funding and personnel appointments on behalf of the Ministry for Higher Education and Research. The statute of the INSU should be reviewed. Under the new CNRS statutes (that also cover the CNRS Institutes), this organizational link has been quashed and the CNRS deems that it is no longer in a position to fund the observatories, considered as operational units.

\subsection{Regulations applicable to seismic events and nuclear installation safety}

In France, seismic regulation is written into the Code known as the Basic Safety Rules, which goes back to 2001 and relies on a deterministic assessment of seismic event probabilities. 
In order to meet the demands of the French Nuclear Safety Authority, the IRSN/BERSSIN (French Bureau for Assessment of Seismic Risks to Safety of Installations - Bureau d'évaluation des risques sismiques pour la sûreté des installations) develops expertise in respect to probability computation thanks to leading-edge research work, of recognised international standing in association with competent academic research laboratories. The operator has developed an extensive programme of collaborative research, with numerous research laboratories and similar bodies, collaborating in the European SIGMA Programme (Research and Development Programme on Seismic Ground Motion). The investigations into seismic probabilities have been subcontracted to private concerns.

Despite the policy statements issued by the IRSN to guarantee transparency (its assessments are made public), we could envision adopting the American practice, based on expert panels and who carry out very in-depth analyses, both by research scientists and operators, dealing precisely with the governance issue and its acceptable forms and with the role of experts in assessing probabilities (cf. for example, the documents produced by the "Seismic Hazard" Panel of the NRC and by the SSHAC Committee (National Regulatory Commission the Senior Seismic Hazard Analysis Committee).

\subsection{Paraseismic protection for installations}

The best protection for the installations lies in the application of paraseismic construction standards and prescriptions. Indubitably, recent experience teaches us that when buildings are erected in conformity with modern standards (viz., later than the decade 1970-1980 approx.), earthquake damage is limited. In all recent major earthquakes, the older buildings brutally collapsed whereas modern buildings, if they comply with paraseismic designs, remained standing.

Correct paraseismic construction calls for special attention at each stage, from the drawing board to the finished structure. If stress is often laid on the dimensional phase, the early design phase and application of appropriate building phase rules are equally important. The aim here is to avoid fragile breaks occurring in certain structural areas that lead to chain reaction breaks (domino effect) and a rapidly progressive collapse sequence. Dimensioning implies that the structural elements are chosen with an adequately high resistance factor.

The "art" of paraseismic protection lies in the capacity of the building to resist forces that are higher than those included in the dimensioning calculations. The level of the external impacting forces can only be defined using probabilistic forecasting: we can thereby accept that this level be exceeded with a probability all the lower, if the building is large or presents a risk vis-à-vis the 
environment. However, is of prime importance that if and when this level is exceeded there will not be an ensuing catastrophe. The answer here seems to be forthcoming in the principle of "capacity dimensioning", akin to using a fuse in an electric circuit. The designers plan energy dissipation areas where the non-elastic deformations are concentrated, with acceptable damage to the building but not its collapse, and other areas which are over dimensioned. This procedure is written into all modern regulations and in particular in the recent Eurocode collection of European standards.

Implementing the concepts set out above is a sensitive process, especially in France. As we know, France has a low seismic history; consequently our civil engineers and builders do not benefit from adequate training in paraseismic techniques. This is all the more evident in SMEs in the construction sector. The problem is less acute in the major public works enterprises who have invested in special training schemes and efforts to make their personnel aware of the underlying issues.

\section{Conclusion}

The cataclysm that struck the North-East coast of Japan on March 1 1, 2011 constitutes a major earthquake event on Earth, major in both intensity and size of the land-area impacted and by the fact that it was accompanied by a huge tsunami.

This megaseism hit a country which has not only the densest geophysical network of sensors in the world, plus a rapid seismic and tsunami alert system using the latest technologies, with the highest anti-tsunami barriers that exist, in a country where the population has the experience of past events and the best earthquake training imaginable, and finally where the scientific excellence of the engineers and research workers has enabled the Japanese to manage properly recent disasters, thanks to the knowledge acquired over the past century. The tragic consequences of this event encourage us to seek out their causes.

Clearly the direct aftermath of the earthquake was correctly handled, both in terms of the Government instructions issued to the population, the good paraseismic design of the main buildings and the automatic reactions of the alert system. Nonetheless, the scale and the extent of the earthquake took the Authorities by surprise.

Neither was the megatsunami predicted by the Japanese Authorities and this was both the cause of tremendous physical damage, notably to the nuclear reactors built near the coast-line and of considerable loss of lives. The Japanese example also throws light on certain questions and issues that should be addressed by France. 
- All studies regarding natural risk factors (earthquakes and tsunamis) should be carried out over periods of time that are sufficiently long to integrate the high degree of irregularity needed to gain valid return data from experience. It is very important that we take account of both historic and geological records. Geological analyses should be developed, notably along the known major fault lines still in activity, in sensitive areas of Metropolitan France, the French West Indies and in the French Pacific territories.

- In the world's major subduction zones land notably in the Caribbean area), France should participate in the international development of studies into, and protection against, megaseisms and associate tsunamis, through collaboration via the permanent measurement and alert networks that can measure seismicity and ground movement as well as variations in sea level and issue warnings in the case of detected and impending tsunamis.

- In this field research activities as well as surveillance and paraseismic standards should integrate the rapidly evolving knowledge base of earth sciences and associated technologies. This work should lead to regularly updated, common standards. Where basic research is concerned, the interactions between the various research teams working in these fields in different research establishments should be encouraged and vitalised. In particular, reflection should be forthcoming in involve the IRSN, the operators and the academics, and should be conducted with the aim to improve, if deemed necessary, the fundamental safety regulation (RFS in French) for nuclear installations, in order to integrate new assessment methodology for probabilistic events.

- Paraseismic construction standards must be complied with whenever builders begin to design a new structure and the completed building must be certified by a qualified authority independent of the prime contractor. Paraseismic construction standards for major infrastructures and industrial sites must be established at a pan-European level, notably when the sites are prepared for nuclear power generation equipment and structural housing or for chemical production plants, with active participation of IRSN, CEA and operators.

- Research and surveillance activities should receive regular financing from varied sources, guaranteed by the State both for the medium and 
long-terms. Studies conducted in relation to natural event probabilities in an operational context, such as assessing faults close to industrial plant that carry a risk factor, e.g., large dams, chemical industrial sites and nuclear power stations, should be carried out directly by the industries concerned.

- The regional "Prefects" (nationally appointed authorities with extensive State delegated powers for certain local and regional affairs), who are responsible for civilian protection and for their delegated administrative powers need to be fully aware of the main characteristics and consequences for natural catastrophes. Specific training should be provided in these matters. Moreover, natural probabilistic events should be addressed in school programmes and be integrated into all citizens' education and cultural backgrounds.

- Research into natural probabilistic events and development of prevention schemes must be seen as being in the general interest and the Japanese example demonstrates clearly that such studies should concentrate equally on governance and pure research aspects of the issues addressed. A National Council for Natural Risks, placed under the authority and reporting to the Prime Minister should be instated and provided with funding from those ministerial departments concerned (Environment, Home Office, Higher Education and Research). Public research and academic representatives sitting on this Council should constitute a majority. 